\title{
siRNA screen of ES cell-derived motor neurons identifies novel regulators of tetanus toxin and neurotrophin receptor trafficking
}

\author{
Marco Terenzio $^{1+}$, Matthew Golding ${ }^{1+}$ and Giampietro Schiavo ${ }^{1,2 *}$ \\ ${ }^{1}$ Molecular NeuroPathobiology Laboratory, Cancer Research UK London Research Institute, London, UK \\ ${ }^{2}$ Sobell Department of Motor Neuroscience and Movement Disorders, UCL Institute of Neurology, University College London, London, UK
}

Edited by:

Lawrence Rajendran, University

Zurich, Switzerland

\section{Reviewed by:}

Robert Weissert, University of Regensburg, Germany

Philipp Koch, University of Bonn,

Germany

\section{*Correspondence:}

Giampietro Schiavo, Sobell

Department of Motor Neuroscience and Movement Disorders, UCL

Institute of Neurology, University

College London, Queen Square,

London, WC1N 3BG, UK

e-mail: giampietro.schiavo@ucl.ac.uk

${ }^{\boldsymbol{t}}$ Present address:

Marco Terenzio, Biological

Chemistry, Weizmann Institute of

Science, Rehovot, Israel:

Matthew Golding, Centre for

Microvascular Research, William

Harvey Research Institute, Barts and

The London School of Medicine and

Dentistry, Queen Mary, University

of London, London, UK
Neurons rely on the long-range transport of several signaling molecules such as neurotrophins and their receptors, which are required for neuronal development, function and survival. However, the nature of the machinery controlling the trafficking of signaling endosomes containing activated neurotrophin receptors has not yet been completely elucidated. We aimed to identify new players involved in the dynamics of neurotrophin signaling endosomes using a medium-throughput unbiased siRNA screening approach to quantify the intracellular accumulation of two fluorescently tagged reporters: the binding fragment of tetanus neurotoxin $\left(\mathrm{H}_{\mathrm{C}} \mathrm{T}\right)$, and an antibody directed against the neurotrophin receptor $p 75^{\mathrm{NTR}}$. This screen performed in motor neurons differentiated from mouse embryonic stem (ES) cells identified a number of candidate genes encoding molecular motors and motor adaptor proteins involved in regulating the intracellular trafficking of these probes. Bicaudal D homolog 1 (BICD1), a molecular motor adaptor with pleiotropic roles in intracellular trafficking, was selected for further analyses, which revealed that $\mathrm{BICD} 1$ regulates the intracellular trafficking of $\mathrm{H}_{\mathrm{C}} \mathrm{T}$ and neurotrophin receptors and likely plays an important role in nervous system development and function.

Keywords: axonal transport, BICD1, embryonic stem cells, endocytosis, tetanus neurotoxin, p75

\section{INTRODUCTION}

The development, maintenance, and function of the vertebrate nervous system rely on a complex network of signaling pathways tightly regulated in space and time by different growth factors. Amongst these, neurotrophins represent a very important class of molecules, which activate two different types of receptors, the Trk family of receptor tyrosine kinases and $\mathrm{p} 75^{\mathrm{NTR}}$, a member of the TNF receptor superfamily. Upon neurotrophin binding at the plasma membrane, Trk receptors are endocytosed and can then either signal locally, or be retrogradely transported along the axon to the neuronal cell body, where they initiate signaling cascades leading to the long-term modulation of gene expression (Heerssen and Segal, 2002).

Different types of neurons express distinct repertoires of Trk receptors, which determine their responsiveness and reliance on specific neurotrophins. In particular, motor neurons located in the ventral horn of the spinal cord express TrkB, TrkC, and $\mathrm{p} 75^{\mathrm{NTR}}$, and functionally connect skeletal muscles with the motor cortex via the corticospinal tract. The survival of motor neurons is ensured in vivo by neurotrophins secreted by their target muscles. Once bound to the motor neuron surface, neurotrophin receptor complexes are transported in axonal signaling endosomes, which ensure the long-range intracellular transport and somatic endocytic sorting of these receptors (Bronfman et al., 2007; Schmieg et al., 2013).

Interestingly, this route constitutes a major gateway for the entry and dissemination of pathogens in the nervous system. Specifically, motor neuron signaling endosomes mediate the axonal transport of neurotropic viruses, such as poliovirus and canine adenovirus 2 (Ohka et al., 2009; Salinas et al., 2009), and clostridial neurotoxins, such as tetanus toxin (TeNT) and botulinum neurotoxin (BoNT) (Restani et al., 2012; Bercsenyi et al., 2013).

TeNT is taken up at the neuromuscular junction (NMJ) and transported to the spinal cord, where it enters inhibitory interneurons and blocks neurotransmitter release (Salinas et al., 2010). The binding fragment of TeNT $\left(\mathrm{H}_{\mathrm{C}} \mathrm{T}\right)$ has been shown to share the same route of internalization and axonal retrograde transport with neurotrophins and their receptors (Deinhardt et al., 2006), and it has the advantages of being non-toxic and readily expressed in a recombinant form with small peptide tags suitable for chemical and fluorescent labeling (Bohnert and Schiavo, 2005; Deinhardt et al., 2006). As such, $\mathrm{H}_{\mathrm{C}} \mathrm{T}$ represents a reliable probe for the analysis of the axonal retrograde transport of signaling endosomes in motor neurons in vitro and in vivo. 
RNAi screens have been widely used to generate complex datasets from image-based analysis of cell lines in highthroughput formats (Krausz, 2007; Demir and Boutros, 2012). However, highly proliferative cell lines do not constitute the most physiologically relevant model system to study postmitotic cells such as neurons. On the other hand, the use of primary motor neurons for high-content image-based RNAi screens presents daunting challenges because of the technical difficulties associated with generating enough cells, transfecting them efficiently and imaging their complex morphology in a quantitative and unbiased manner.

In spite of these obstacles, we developed a reliable protocol to transfect motor neurons with a library of short interference RNAs (siRNA) targeting a panel of molecular motors and their adaptors. This screen identified a small cohort of genes, which affected the intracellular accumulation of $\mathrm{H}_{\mathrm{C}} \mathrm{T}$ and $\mathrm{p} 75^{\mathrm{NTR}}$ when silenced. Knockdown of one gene in particular, bicaudal $D$ homolog 1 (Bicd1) yielded an increased internalization phenotype for $\mathrm{H}_{\mathrm{C}} \mathrm{T}$ and was selected for further analyses, which demonstrated that BICD1 depletion also increased the intracellular accumulation of ligand-bound $\mathrm{p} 75^{\mathrm{NTR}}$ and TrkB (Terenzio et al., 2014).

BICD1 is known to be involved in intracellular trafficking, dynein-mediated transport (Hoogenraad et al., 2001; Matanis et al., 2002; Bianco et al., 2010; Aguirre-Chen et al., 2011), and has important roles in the development and function of the Drosophila and C. elegans nervous systems (Li et al., 2010). We now show that BICD1 is a key regulator of $\mathrm{H}_{\mathrm{C}} \mathrm{T}$ and neurotrophin receptor dynamics and performs this role by controlling the endocytic sorting of $\mathrm{H}_{\mathrm{C}} \mathrm{T}$ and neurotrophin receptors to regulate their recycling to the plasma membrane. Our data identify a novel function for BICD1 as a modulator of axonal signaling endosome dynamics, which may also be relevant for different growth factor receptors and virulence factors in other cellular systems.

\section{MATERIALS AND METHODS ETHICS STATEMENT}

All experiments were carried out following the guidelines of the Cancer Research UK genetic manipulation procedures.

\section{REAGENTS AND ANTIBODIES}

All chemicals were supplied by Sigma, unless stated otherwise. Tissue culture media and supplements were from Life Technologies.

The $\beta$ III tubulin (TUJ1) antibody was from Covance and the Vamp2 antibody (clone 69.1) was from Synaptic Systems. The characterization of the polyclonal antibody against the extracellular domain of $\mathrm{p}^{\mathrm{NTR}}\left(\alpha \mathrm{p} 75^{\mathrm{NTR}} ; 5411\right)$ was previously described (Deinhardt et al., 2007). The Vps26 antibody was a kind gift of Matthew Seaman (University of Cambridge, UK).

\section{MOTOR NEURON CULTURES}

For the preparation of embryonic stem (ES) cell-derived motor neurons, ES cells were maintained on fish skin gelatin coated flasks in Glasgow Minimal Essential Medium (GMEM), $5 \%$ ES cell-qualified foetal bovine serum (FBS), 5\% knockout serum replacement (KSR), 1\% GLUTAMAX, $0.1 \mathrm{mM}$ 2-mercaptoethanol and 1000 units/ml of leukaemia inhibitory factor (ESGRO, Millipore). To generate motor neurons, $1.5 \times$ $10^{6}$ ES cells were grown in suspension on a $10 \mathrm{~cm}$ non-tissue culture treated Petri dish containing differentiation (DFNK) medium: 45\% Neurobasal, 45\% DMEM/Ham's-F12, 10\% KSR, 1\% GLUTAMAX and 0.1 mM 2-mercaptoethanol.

The following day, EBs were gently centrifuged and resuspended in $10 \mathrm{ml}$ of fresh DFNK medium and plated on a new Petri dish. $24 \mathrm{~h}$ later, the greatly enlarged EBs were allowed to sediment by gravity and re-suspended in fresh DFNK medium supplemented with $1 \mu \mathrm{M}$ all-trans retinoic acid (RA) and $333 \mathrm{nM}$ Smoothened Agonist (SAG; Enzo Life Sciences). EBs were maintained under these conditions for a further 4 days with the medium changed every other day. EBs were then dissociated with $0.025 \%$ porcine pancreatic trypsin in $1 \mathrm{ml} \mathrm{PBS}$ for $7 \mathrm{~min}$ at $37^{\circ} \mathrm{C}$ and processed as described previously for the dissociation of mouse primary E13.5 spinal cord motor neurons (Hafezparast et al., 2003).

Cells were plated onto poly-D-ornithine and laminin coated dishes in motor neuron growth medium: neurobasal medium supplemented with $2 \% \mathrm{~B} 27,2 \%$ heat-inactivated horse serum, 1\% GLUTAMAX, $25 \mu \mathrm{M}$ 2-mercaptoethanol, $10 \mathrm{ng} / \mathrm{ml}$ rat ciliary neurotrophic factor (CNTF; R\&D Systems), $100 \mathrm{pg} / \mathrm{ml}$ rat glial cell line-derived neurotrophic factor (GDNF; R\&D Systems) and $1 \mu \mathrm{M}$ RA.

\section{GENERATION OF HOMOZYGOUS RRP227 ES CELLS}

Mouse ES cells with a gene-trap insertion in the first intron of Bicd1 (RRP227; http://www.informatics.jax.org/javawi2/servlet/ WIFetch?page $=$ alleleDetailandkey $=544886)$ were obtained from the Mutant Mouse Regional Resource Center. Homozygous Bicd $1^{\text {gt/gt }}$ cells were generated as previously described in Lefebvre et al. (2001) and Terenzio et al. (2014).

\section{CELL TRANSFECTION}

Full length mouse Bicd1 cDNA (MGC-27566, LGC Promochem) was cloned into the EcoR1/BamH1 sites of the EGFP-N1 vector (Clontech) and microinjected into motor neurons as previously described (Deinhardt et al., 2006). BICD1-GFP expressing cells were imaged after $24 \mathrm{~h}$ using an inverted LSM510 confocal microscope (Zeiss). N2A cells were cultured and transfected as previously described (Terenzio et al., 2014).

\section{SIRNA DELIVERY PROTOCOL OPTIMIZATION}

An individual mix was prepared for 23 different lipid-based transfection reagents $(0.25 \mu \mathrm{l}$ of the reagent and $9.75 \mu \mathrm{l}$ OptiMEM per well). Ten micro liters of this mixture were added to $10 \mu$ l VAMP2 siRNA diluted in OptiMEM. The transfection mix was then dispensed into each well of poly-D-ornithine/laminin coated 96-well glass bottomed plates (IWAKI) and incubated at room temperature for $20 \mathrm{~min}$. For each well, $3.5 \times 10^{4} \mathrm{HBG} 3 \mathrm{ES}$ cell-derived motor neurons (Wichterle et al., 2002) suspended in $80 \mu \mathrm{l}$ of motor neuron growth medium were plated on top of the transfection mixture. After $72 \mathrm{~h}$ incubation, motor neurons we fixed in $4 \%$ paraformaldehyde (PFA) and immunostained for VAMP2 and $\beta$ III tubulin.

The Thermo Scientific ${ }^{\mathrm{TM}}$ ArrayScan $^{\mathrm{TM}}$ XTI High Content Analysis Reader was used for automated image collection and 
image analysis was performed using the spot counting algorithm. To assess transfection-related toxicity, each transfection reagent was scored on the basis of the number of viable and morphologically intact motor neurons remaining after transfection. Based on favorable cell viability scores and effective knockdown of VAMP2 protein levels, eight transfection reagents were then selected for a second round of validation. Dreamfect Gold (OZ Biosciences) was chosen to conduct the siRNA screen as it proved to be the most effective in reliably inducing VAMP2 knock-down in both primary and ES cell-derived motor neurons in a 96-well format using the aforementioned reverse transfection protocol.

\section{SIRNA SCREENING}

A master mix of Dreamfect Gold transfection reagent sufficient for the entire siRNA library targeting 133 genes was prepared $(0.25 \mu \mathrm{l}$ Dreamfect Gold and $9.75 \mu$ l OptiMEM per well) and $10 \mu \mathrm{l}$ added to each well of another 96-well plate containing $10 \mu \mathrm{l}$ siRNA (50 nM siRNA in OptiMEM) targeting a single gene (Supplementary Table 1A, B). Twenty micro liters of transfection mix were then dispensed into each well of poly-Dornithine/laminin coated 96-well glass bottomed plates (IWAKI) and incubated at room temperature for $20 \mathrm{~min}$ to $1 \mathrm{~h}$. For each well, $3.5 \times 10^{4}$ HBG3 ES cell derived motor neurons suspended in $80 \mu \mathrm{l}$ of motor neuron growth medium were plated on top of the transfection mixture ( $50 \mathrm{nM}$ final concentration for each siRNA). The cells were then left to grow for $72 \mathrm{~h}$ before performing the internalization assay.

To assess for probe internalization, the growth medium was removed and replaced with Neurobasal medium containing $20 \mathrm{nM}$ AlexaFluor555-conjugated $\mathrm{H}_{\mathrm{C}} \mathrm{T}$ and $0.4 \mu \mathrm{g} / \mathrm{ml} \alpha \mathrm{p} 75^{\mathrm{NTR}}$ (Deinhardt et al., 2007). Positive control wells previously incubated with RISC-free siRNA (Qiagen) were additionally supplemented with $1 \mathrm{mM}$ EHNA. Motor neurons were then allowed to internalize the probes at $37^{\circ} \mathrm{C}$ for $2 \mathrm{~h}$, cooled on ice for $5 \mathrm{~min}$, acid-washed (100 $\mathrm{mM}$ citric acid $\mathrm{pH} 2.0,142 \mathrm{mM} \mathrm{NaCl})$ for $2 \mathrm{~min}$, washed and fixed with $4 \% \mathrm{w} / \mathrm{v}$ PFA for $20 \mathrm{~min}$. To detect internalized $\alpha p 75^{\mathrm{NTR}}$, cells were immunostained with antirabbit AlexaFluor647-conjugated secondary antibody. Finally, each plate was sealed and 16 confocal Z-stacks were acquired for each well using an inverted LSM510 confocal microscope (Zeiss). Internalized probes were quantified using Cell Profiler as described in the data quantification section.

\section{TRANSMISSION ELECTRON MICROSCOPY}

$\mathrm{H}_{\mathrm{C}} \mathrm{T}$ was conjugated to colloidal gold by mixing $250 \mu \mathrm{g}$ of purified $\mathrm{H}_{\mathrm{C}} \mathrm{T}$ in $0.5 \mathrm{ml}$ of $2 \mathrm{mM}$ sodium tetraborate to $1 \mathrm{ml}$ of colloidal gold particles ( $10 \mathrm{~nm}$; British Biocell) as described elsewhere Terenzio et al. (2014).

Motor neurons plated on coverslips were incubated with $20 \mathrm{nM}$ nanogold-conjugated $\mathrm{H}_{\mathrm{C}} \mathrm{T}$ for $2 \mathrm{~h}$ at $37^{\circ} \mathrm{C}$ prior to washing. Cells were fixed in $2.5 \%$ glutaraldehyde, $4 \%$ PFA in Sorensen's phosphate buffer at room temperature for $20 \mathrm{~min}$, postfixed in osmium tetroxide, stained with tannic acid and dehydrated progressively up to $100 \%$ ethanol. Finally, coverslips were embedded in an Epon epoxy resin, sectioned $(70-75 \mathrm{~nm})$ and stained with lead citrate. Images were acquired using a Tecnai Spirit Biotwin (FEI) transmission electron microscope.

\section{ASSESSMENT OF AXONAL RETROGRADE TRANSPORT}

Axonal retrograde transport kinetics of $\mathrm{H}_{\mathrm{C}} \mathrm{T}$ and $\alpha \mathrm{p} 75^{\mathrm{NTR}}$ in wild type and in Bicd $1^{\text {gt/gt }}$ motor neurons was performed as previously described (Lalli and Schiavo, 2002; Deinhardt et al., 2006) and quantified using Motion Analysis software (Kinetic Imaging) (Bohnert and Schiavo, 2005; Deinhardt et al., 2006).

\section{IMMUNOFLUORESCENCE}

Motor neurons were seeded onto poly-D-ornithine and laminincoated coverslips and maintained under standard culture conditions for 4-5 days. Cells were then fixed with 4\% PFA for $15 \mathrm{~min}$ at room temperature, washed and blocked with $2 \%$ bovine serum albumin (BSA) in PBS containing $0.2 \%$ Triton X-100 for $20 \mathrm{~min}$ at room temperature. Coverslips were then incubated for $1 \mathrm{~h}$ with primary antibodies followed by AlexaFluor-conjugated secondary antibodies (1:500; Life Technologies). Finally, samples were postfixed with PFA and mounted in Mowiol.

\section{WESTERN BLOTTING}

SDS-PAGE was performed using 4-12\% NuPAGE Bis-Tris gradient gels (Life Technologies) according to the manufacturer's instructions and blotted onto polyvinylidene fluoride (PVDF) membranes (Millipore). Membranes were blocked in 5\% skimmed milk dissolved in Tris-buffered saline (TBS) containing $0.05 \%$ Tween-20 (TBST) for $1 \mathrm{~h}$ at room temperature and then incubated with primary antibodies diluted $1: 1000$ or 1:2000 in TBST for $1 \mathrm{~h}$ at room temperature or overnight at $4^{\circ} \mathrm{C}$. Blots were then washed and incubated with appropriate HRP-conjugated secondary antibodies (GE Healthcare). Immunoreactivity was detected using Luminata or Crescendo ECL substrates (Millipore) and ECL-Hyperfilm (GE-Healthcare).

\section{DATA QUANTIFICATION}

Quantification of western blots and immunofluorescence staining was performed using ImageJ for all experiments except the siRNA screen and the validation re-screen. Typically, the fluorescence staining of the area of interest was thresholded and the number of thresholded voxels measured. Immunostaining for neuronalspecific proteins, such as $\beta$ III tubulin, was used for normalization purposes.

For the siRNA screen, image quantification of fluorescent $\mathrm{H}_{\mathrm{C}} \mathrm{T}$ and $\alpha \mathrm{p} 75^{\mathrm{NTR}}$ was performed using Cell Profiler (http://www. cellprofiler.org). RGB images were split and the green GFP channel (motor neuron reporter) was used to create a cell mask, which was then subtracted from the red AlexaFluor555- $\mathrm{H}_{\mathrm{C}} \mathrm{T}$ and blue AlexaFluor647- $\alpha \mathrm{p} 75^{\mathrm{NTR}}$ channels (Figure 2A). Individual $\mathrm{H}_{\mathrm{C}} \mathrm{T}$ and $\mathrm{p} 75^{\mathrm{NTR}}$-positive organelles were then identified in each motor neuron and quantified.

\section{RESULTS \\ VALIDATION OF ES CELL-DERIVED MOTOR NEURONS FOR HIGH-THROUGHPUT IMAGE ANALYSIS}

A key requisite to successfully perform an siRNA screen is the ability to reliably and efficiently deliver RNA duplexes to the cytoplasm of target cells. However, motor neurons are notoriously difficult to transfect using conditions that do not affect their intracellular trafficking (Deinhardt and Schiavo, 2005). To overcome this technical challenge, we established a lipid-based reverse 


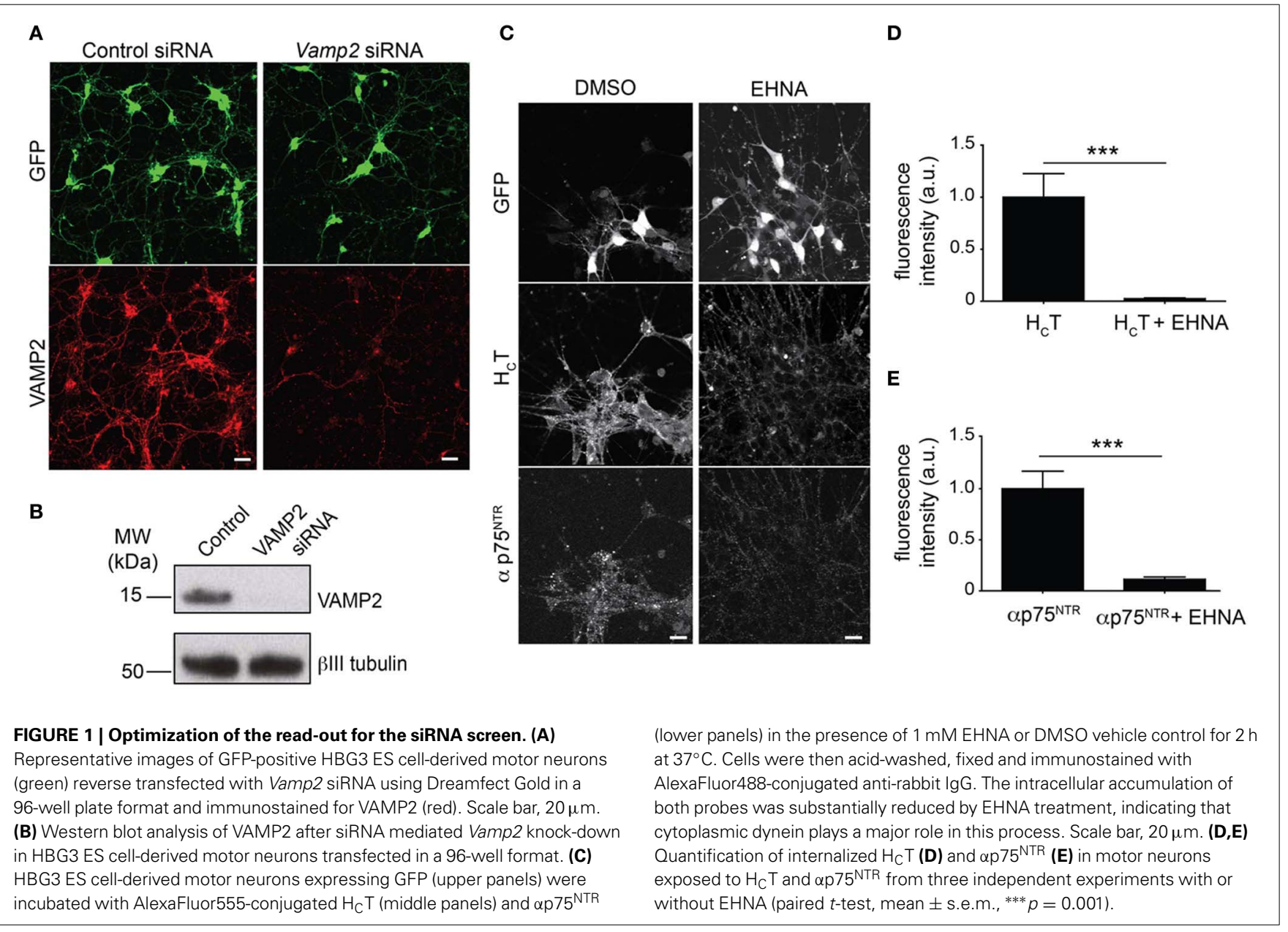

transfection method in primary motor neurons, which could be adapted to a 96-well plate format (see Material and Methods). To optimize the conditions required for efficient gene knockdown in preparation for the siRNA screen, we targeted VAMP2, since loss of this abundant SNARE protein does not affect neuron survival (Schoch et al., 2001). After testing 23 different transfection reagents, some of which are shown in Supplementary Figure 1, Dreamfect Gold (OZ Biosciences) was chosen on the basis of its ability to efficiently induce VAMP2 knockdown in primary motor neurons 3 days after transfection. Importantly, DreamFect Gold induced efficient depletion of VAMP2 without affecting cell viability or morphology (data not shown).

Because of the limited amount of material and the intrinsic cellular heterogeneity of embryo-derived primary motor neuron cultures, we resorted to using transgenic HB9-GFP (HBG3) ES cells to generate the large number of GFP-positive motor neurons necessary for our screen and was a prerequisite for the medium throughput imaging-based approach planned for this project.

HB9-GFP ES cells were readily expanded and differentiated into motor neurons with the expression of GFP driven by the Hb9 homeobox gene enhancer, which facilitates the unequivocal identification of motor neurons (Supplementary Figure 2) (Wichterle et al., 2002). We then confirmed that the transfection protocol previously optimized for primary cells in a 96-well format was also effective in efficiently knocking down VAMP2 in HB9-GFP ES cell-derived motor neurons in the same format (Figures 1A,B).

\section{BIOLOGICAL READ-OUT OF THE SIRNA SCREEN}

The aim of our siRNA screen was to identify new components of the machinery responsible for the uptake and intracellular trafficking of $\mathrm{H}_{\mathrm{C}} \mathrm{T}$ and $\mathrm{p} 75^{\mathrm{NTR}}$, with regulators of axonal retrograde transport being of particular interest for us. However, screening for changes in axonal transport in motor neurons using an automated imaging approach is technically challenging since it would require adapting our established live cell axonal retrograde transport assay (Lalli et al., 2003; Bohnert and Schiavo, 2005; Deinhardt et al., 2006; Restani et al., 2012) to a 96-well plate format.

A simplified protocol was therefore used to monitor the somatic accumulation of $\mathrm{H}_{\mathrm{C}} \mathrm{T}$ and $\mathrm{p} 75^{\mathrm{NTR}}$ in the cell body over time, as a proxy for the retrograde transport of these probes from the axonal network. Motor neurons were thus incubated with fluorescent $\mathrm{H}_{\mathrm{C}} \mathrm{T}$ and an antibody directed against the extracellular domain of $\mathrm{p} 75^{\mathrm{NTR}}$ ( $\alpha \mathrm{p} 75^{\mathrm{NTR}}$ ) for $2 \mathrm{~h}$, before removing the remaining surface-bound probes by acid washing and quantifying 
probe accumulation in the cell bodies of GFP-positive motor neurons. Whilst the endocytosis of $\mathrm{H}_{\mathrm{C}} \mathrm{T}$ into the somato-dendritic compartment is very rapid, the onset of axonal transport of this probe takes considerably longer (Bohnert and Schiavo, 2005). We determined that $2 \mathrm{~h}$ was the ideal end point for our assay because this allowed sufficient time for $\mathrm{H}_{\mathrm{C}} \mathrm{T}$ internalized at distal entry sites to be transported and accumulate in the soma (Supplementary Figure 3A).

The co-incubation of selected samples with EHNA, a known inhibitor of the dynein-mediated retrograde transport of $\mathrm{H}_{\mathrm{C}} \mathrm{T}$ (Lalli et al., 2003), served as positive controls for the decreased intracellular accumulation of both probes (Figures 1C-E), which enter largely overlapping trafficking pathways (Lalli and Schiavo, 2002; Deinhardt et al., 2006). However, in contrast to the overt effect of EHNA on $\mathrm{H}_{\mathrm{C}} \mathrm{T}$ accumulation, which was visible throughout the time frame of the assay (Supplementary Figure 3A), the effects of dynein inhibition on $\mathrm{p} 75^{\mathrm{NTR}}$ accumulation only became apparent after $90 \mathrm{~min}$ (Supplementary Figure 3B).

Notably, the internalization kinetics of $\alpha p 75^{\mathrm{NTR}}$ when incubated alone overlapped with the $\alpha \mathrm{p} 75^{\mathrm{NTR}}$ accumulation profile when cells were co-incubated with this antibody together with $\mathrm{H}_{\mathrm{C}} \mathrm{T}$ and EHNA (Supplementary Figure 3B). This result was not unexpected since it agrees with previous findings showing that in the absence of $\mathrm{H}_{\mathrm{C}} \mathrm{T}$ or neurotrophins, p75 ${ }^{\mathrm{NTR}}$ enters a local fast recycling pathway, and as such does not undergo long-range dynein mediated transport (Deinhardt et al., 2007). Therefore, treatment of motor neurons with EHNA in the absence of $\mathrm{H}_{\mathrm{C}} \mathrm{T}$ was not expected to alter $\alpha \mathrm{p} 75^{\mathrm{NTR}}$ accumulation (see Discussion).

\section{SIRNA SCREENING FOR MODULATORS OF AXONAL RETROGRADE TRANSPORT AND ENDOCYTIC SORTING}

Having established a robust experimental platform for the siRNA screen, HB9-GFP motor neurons were then transfected with a custom-selected siRNA library targeting molecular motors, their adaptors and associated proteins, which have been reported to regulate motor activity (Supplementary Table 1A). To monitor knockdown efficiency under the experimental conditions used for the screen, we determined the down-regulation of VAMP2 in the three independent replicates assayed from the 96-well plates used for the actual screen. As shown in Supplementary Figure 4, VAMP2 knockdown in Vamp2 siRNA treated wells was consistently $80 \%$ or greater.

The accumulation of $\mathrm{H}_{\mathrm{C}} \mathrm{T}$ and $\alpha \mathrm{p} 75^{\mathrm{NTR}}$ was quantified for all siRNAs by scoring the average number of $\mathrm{H}_{\mathrm{C}} \mathrm{T}$ - and $\mathrm{p} 75^{\mathrm{NTR}}$ positive puncta per motor neuron using confocal microscopy followed by multi-parametric image analysis (Figure 2A) and represented as Z-scores (Figure 2B). Candidate hits were selected based on their standard deviations from the mean values for the whole siRNA library (see Materials and Methods and Supplementary Tables 1C,D) and are highlighted on the Z-score profile (Figure 2B).

From this primary analysis, 23 candidate genes for $\mathrm{H}_{\mathrm{C}} \mathrm{T}$ and 28 for $\alpha p 75^{\mathrm{NTR}}$ were taken forward for validation using siRNA pools from a different supplier. The same assay was then performed for the re-screen except that hits were instead selected based on the standard deviation from the mean of the siRNA

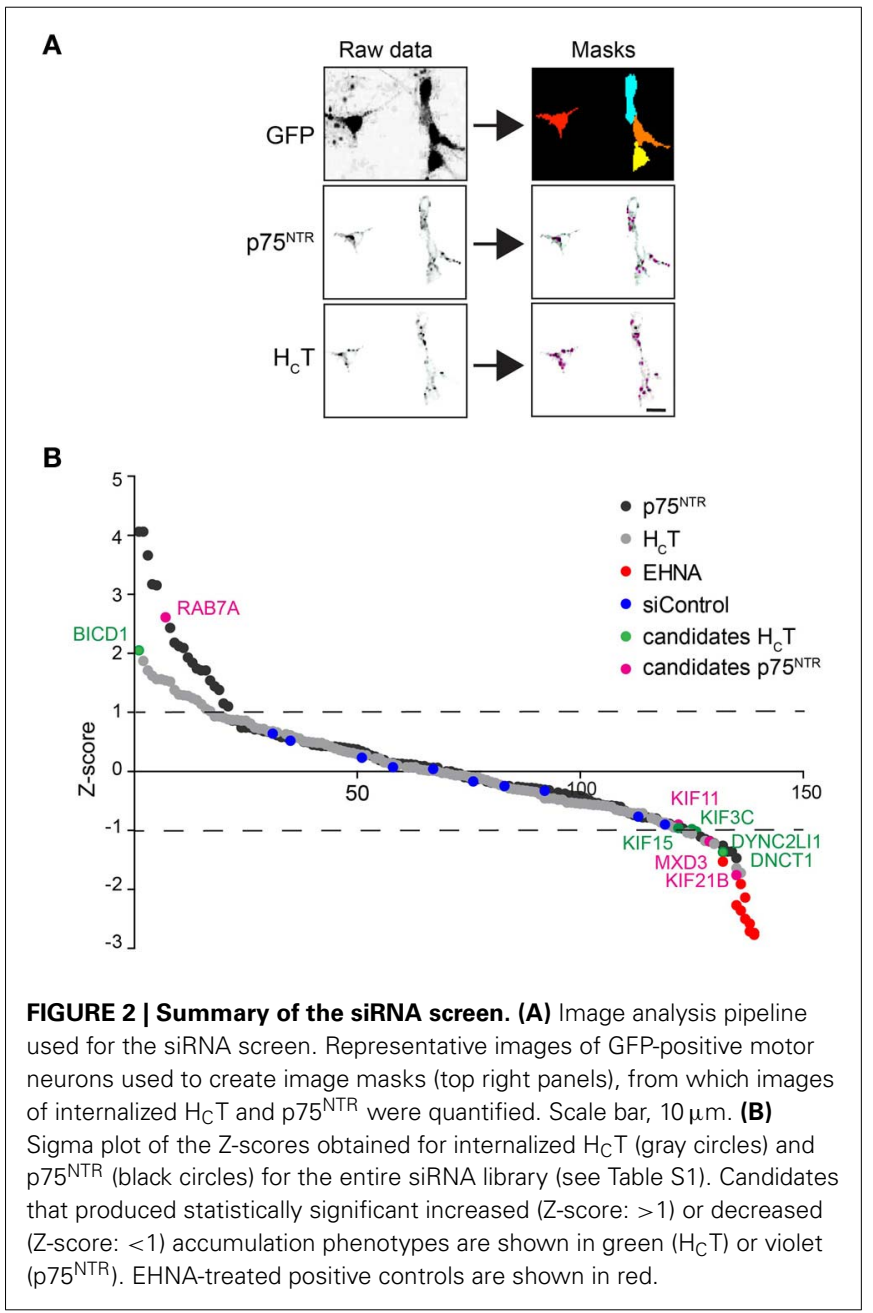

controls (Supplementary Tables 1E-G). RNAi of seven genes was confirmed to decrease probe accumulation, whereas only one gene for each probe was validated to induce the opposite effect (Supplementary Tables 1F,G). Rab7 knockdown led to an increased intracellular accumulation of $\alpha p 75^{\mathrm{NTR}}$ (see Discussion), whilst the only silenced gene that was confirmed to boost the intracellular build-up of $\mathrm{H}_{\mathrm{C}} \mathrm{T}$ was Bicd1 (Figure 2B and Supplementary Tables $1 F, G)$.

We decided to focus our efforts on addressing the role played by BICD1 in $\mathrm{H}_{\mathrm{C}} \mathrm{T}$ trafficking in our model system since BICD1 and the related proteins BICD2 and BICDR1/2 have been described as microtubule-associated proteins and motor adaptors (Hoogenraad et al., 2001; Matanis et al., 2002; Schlager et al., 2010; Terenzio and Schiavo, 2010). Furthermore, BICD1 was proposed to play a role in axonal retrograde transport in neurons (Wanschers et al., 2007).

\section{THE AXONAL RETROGRADE TRANSPORT OF HCT IS NOT AFFECTED IN Bicdl $^{\text {gt/gt }}$ MOTOR NEURONS}

Although RNA interference has emerged as a key strategy to analyse the function of mammalian genes and much work has centered on siRNA design to improve target specificity, individual siRNAs have nevertheless been shown to down-regulate 
unrelated genes by binding to the $3^{\prime}$ untranslated regions of mRNAs resulting in off-target effects (Echeverri et al., 2006). To discount this possibility and confirm the specificity of the $\mathrm{H}_{\mathrm{C}} \mathrm{T}$ accumulation phenotype induced by Bicdl knockdown, we independently assessed the effects of BICD1 depletion in motor neurons derived from an ES cell line engineered to carry a Bicd1 gene trapped allele, Bicd1 ${ }^{\text {gt/ }}$ (Terenzio et al., 2014). Motor neurons derived from ES cells homozygous for this mutation $\left(\mathrm{Bicd}^{\mathrm{gt} / \mathrm{gt}}\right)$ expressed $70 \%$ lower BICD1 protein compared to wild type cells. Importantly, Bicd ${ }^{\text {gt/gt }}$ motor neurons were indistinguishable from Bicd $1^{\mathrm{gt} /+}$ and wild-type ES cell-derived motor neurons in terms of synaptic density or neurite differentiation (Terenzio et al., 2014). As such, Bicd $1^{\text {gt/gt }}$ motor neurons are an ideal model to study the effects of BICD1 depletion on $\mathrm{H}_{\mathrm{C}} \mathrm{T}$ trafficking.

Confirming the previous findings linking BICD1 to axonal transport (Wanschers et al., 2007), BICD1-GFP transfected into wild-type motor neurons underwent robust retrograde transport along the axonal network (Figure 3A). However, in spite of the reported interaction of BICD1 with cytoplasmic dynein, BICD1 does not appear to play a direct role in this pathway, since axonal retrograde transport of $\mathrm{H}_{\mathrm{C}} \mathrm{T}$ was not perturbed in Bicd1 ${ }^{\mathrm{gt} / \mathrm{gt}}$ motor neurons (Figure 3B).

\section{BICD1 DEPLETION ENHANCES THE SOMATIC ACCUMULATION OF $\mathrm{H}_{\mathbf{C}} \mathbf{T}$}

To confirm that the depletion of BICD1 in Bicd $1^{\text {gt/gt }}$ motor neurons replicated the $\mathrm{H}_{\mathrm{C}} \mathrm{T}$ accumulation phenotype identified during the siRNA screen, identical probe accumulation assays were performed using Bicd1 $1^{\mathrm{gt} /+}$ and $\mathrm{Bicd} 1^{\mathrm{gt} / \mathrm{gt}}$ motor neurons. Thus, $\mathrm{H}_{\mathrm{C}} \mathrm{T}$ and $\alpha \mathrm{p} 75^{\mathrm{NTR}}$ were incubated together to trigger the internalization of $\mathrm{p} 75^{\mathrm{NTR}}$ via a clathrin-dependent route linked to axonal retrograde transport (Deinhardt et al., 2007). Probe internalization was quantified at 15,30 , and $60 \mathrm{~min}$ of incubation at $37^{\circ} \mathrm{C}$, which demonstrated that the intracellular accumulation of both $\mathrm{H}_{\mathrm{C}} \mathrm{T}$ and $\alpha \mathrm{p} 75^{\mathrm{NTR}}$ was significantly increased in Bicd $1^{\mathrm{gt} / \mathrm{gt}}$ motor neurons after $60 \mathrm{~min}$ (Supplementary Figure 5). This phenotype was also detected in Bicd $1^{\text {gt } /+}$ cells, although it was statistically significant only for $\mathrm{p} 75^{\mathrm{NTR}}$ under these experimental conditions (Supplementary Figure 5B).

These data supported the results of our siRNA screen and further confirmed that depletion of BICD1 causes an increased somatic accumulation of $\mathrm{H}_{\mathrm{C}} \mathrm{T}$. However, a similar phenotype for the $\mathrm{p} 75^{\mathrm{NTR}}$ antibody was also observed in the Bicd $1^{\mathrm{gt} /+}$ model system, prompting us to further investigate the effects of BICD1 depletion on the trafficking of the neurotrophin receptors $\mathrm{p} 75^{\mathrm{NTR}}$ and $\operatorname{TrkB}$, which are described elsewhere (Terenzio et al., 2014). Altogether, our data indicate that BICD1 functions as a regulator of the somatic sorting of signaling endosomes containing in $\mathrm{H}_{\mathrm{C}} \mathrm{T}$ and neurotrophin receptors. However, this manuscript focuses primarily on investigating the regulatory role of BICD1 on $\mathrm{H}_{\mathrm{C}} \mathrm{T}$ trafficking.

\section{BICD1 DEPLETION CAUSED THE INCREASED ASSOCIATION OF H $\mathrm{H}_{\mathrm{C}} \mathrm{T}$ WITH ENDOSOMAL SORTING COMPARTMENTS}

In order to investigate the precise trafficking step affected by BICD1 depletion, we used transmission electron microscopy to trace the intracellular fate of internalized nanogold-conjugated $\mathrm{H}_{\mathrm{C}} \mathrm{T}$ in wild type and Bicd $1^{\text {gt/gt }}$ motor neurons. As previously reported, colloidal gold-conjugated $\mathrm{H}_{\mathrm{C}} \mathrm{T}$ undergoes rapid internalization followed by axonal retrograde transport and accumulates in organelles resembling tubular endosomes and multivesicular bodies (MBV) (Parton et al., 1987; Lalli et al., 2003). Whilst this distribution pattern of $\mathrm{H}_{\mathrm{C}} \mathrm{T}$ was confirmed in wildtype motor neurons (Figure 4A), BICD1 depletion induced a preferential accumulation in $\mathrm{H}_{\mathrm{C}} \mathrm{T}$ and enlarged organelles with amorphous content, which were localized in the cell body of Bicd $1^{\text {gt/gt }}$ motor neurons (Figures $4 B-D$ ). These organelles contained clustered gold-conjugated $\mathrm{H}_{\mathrm{C}} \mathrm{T}$, which was localized close to the limiting membrane and occasionally within buds or tubules emerging from these structures (Figure 4B).

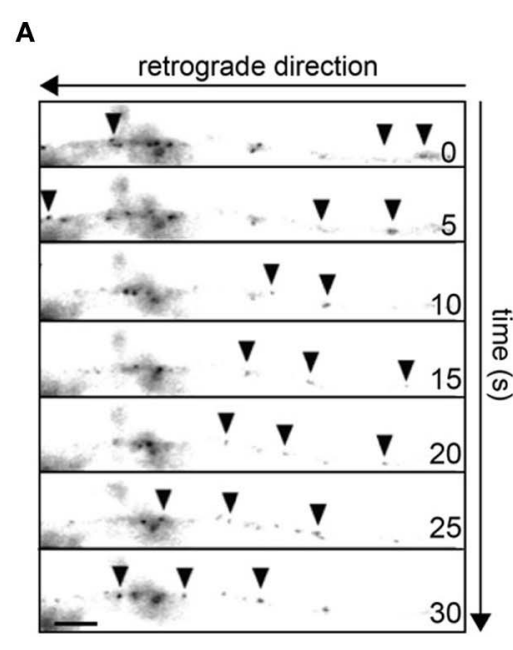

FIGURE 3 | Axonal retrograde transport of $\mathrm{H}_{\mathrm{C}} \mathrm{T}$ is not perturbed in Bicd 19t/gt motor neurons. (A) Representative images taken from a time-lapse movie showing retrograde movement of BICD1-GFP (arrowheads) along the axon of a wild type motor neuron. Scale bar,
B

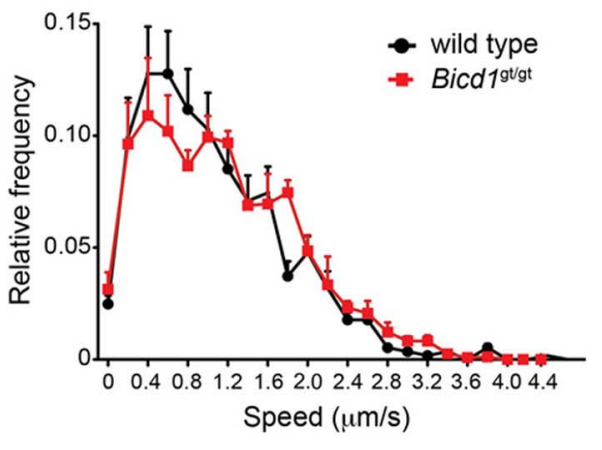

$5 \mu \mathrm{m}$. (B) Speed distribution profiles of axonal AlexaFluor-conjugated $\mathrm{H}_{\mathrm{C}} \mathrm{T}$-positive carriers undergoing axonal retrograde transport in wild type (black squares) and Bicd $1^{\mathrm{gt} / \mathrm{gt}^{\mathrm{t}}}$ (red squares) motor neurons (mean \pm s.e.m.). 


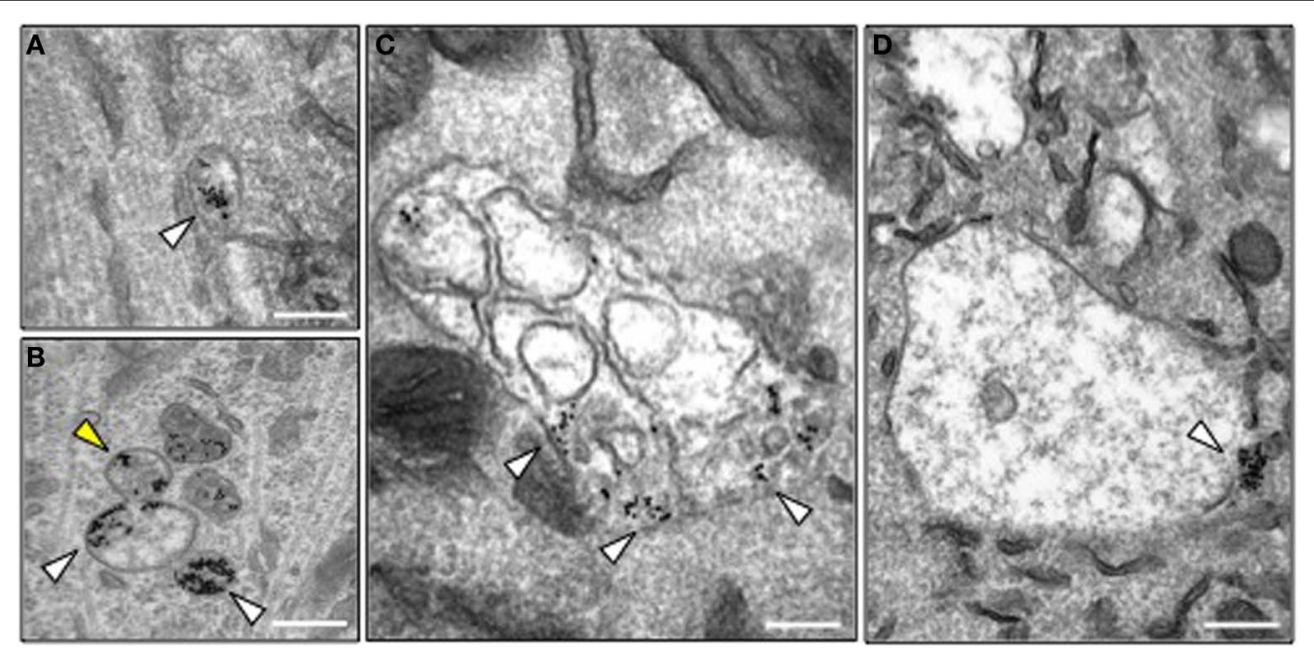

FIGURE 4 | Morphology of $\mathrm{H}_{\mathrm{C}} \mathrm{T}$-containing organelles in wild type and Bicd 19t/gt motor neurons. (A) Transmission electron microscopy image of a typical endosome containing gold-conjugated $\mathrm{H}_{\mathrm{C}} \mathrm{T}$ (white arrowhead) in wild type motor neurons. $\mathrm{H}_{\mathrm{C}} \mathrm{T}$ was internalized for $2 \mathrm{~h}$ at $37^{\circ} \mathrm{C}$. Scale bar, $200 \mathrm{~nm}$. (B-D) Transmission electron microscopy images of representative organelles containing gold-conjugated $\mathrm{H}_{C}{ }^{\top}$ (white arrowheads) in Bicd 19t/gt motor neurons following internalization for $2 \mathrm{~h}$ at $37^{\circ} \mathrm{C}$. $\mathrm{H}_{\mathrm{C}} \mathrm{T}$ was often detected in budding structures (B, yellow arrowhead), or enlarged endosomal organelles containing membranes (C) or with an amorphous content (D). In several instances, gold-conjugated $\mathrm{H}_{\mathrm{C}}{ }^{\top}$ was found clustered at the limiting membrane of these structures. Scale bar, $200 \mathrm{~nm}$.
We believe that the organelles containing large clusters of gold-conjugated $\mathrm{H}_{\mathrm{C}} \mathrm{T}$ represent enlarged endosomal sorting compartments. This view is supported by the observation that $\mathrm{H}_{\mathrm{C}} \mathrm{T}$ co-localized with components of the retromer complex, such as Vps26 (Figures 5A,B) and sorting nexin 1 (SNX1) (Terenzio et al., 2014). Furthermore, BICD1 was found to partially co-distribute with selected endosomal markers, such as VTI1B (Figure 5C), a SNARE protein involved in late endosome to lysosome trafficking (Offenhauser et al., 2011). This result suggested that BICD1 might be important for this sorting route, which normally controls the down-regulation of ligand-activated receptor complexes. However, we never observed any co-localization between $\mathrm{H}_{\mathrm{C}} \mathrm{T}$ and BICD1 (Figure 5D) or VTI1B (data not shown), suggesting either that the association of BICD1 with these markers was below the detection limits of our assays, or that BICD1 affected $\mathrm{H}_{\mathrm{C}} \mathrm{T}$ behavior indirectly by altering endosomal sorting steps downstream of SNX1.

\section{BICD1 DEPLETION INCREASES $\mathrm{H}_{\mathrm{C}}$ T BINDING TO THE NEURONAL PLASMA MEMBRANE}

The retromer complex is an essential component of the endosomal protein sorting machinery, which regulates the retrieval of cargoes in transit through the endosomal pathway to the Golgi or their re-targeting back to the plasma membrane. Misregulation of retromer-mediated sorting impairs these processes and causes severe neurological diseases, such as hereditary spastic paraplegia (Seaman, 2012). Whereas targeting to the Golgi was unaffected by BICD1 depletion (Terenzio et al., 2014 and data not shown), the binding of $\mathrm{H}_{\mathrm{C}} \mathrm{T}$ to the plasma membrane was significantly enhanced in Bicd ${ }^{\text {gt/gt }}$ motor neurons compared to wild-type cells (Figure 6). Similarly, TrkB and p75 also showed increased accumulation on the plasma membrane of mutant neurons (Terenzio et al., 2014).

\section{DISCUSSION}

In this work, we have developed a novel siRNA screening approach designed to identify new players involved in the internalization and trafficking of tetanus toxin and neurotrophin receptor complexes in motor neurons. We designed an imagingbased assay using a 96-well plate format, which allowed us to screen a custom-selected siRNA library for genes affecting the trafficking of neurotropic probes. Important considerations for protocol design included the selection of appropriate fluorescent probes and a relevant cell model to monitor their intracellular trafficking.

To this end, we chose $\mathrm{H}_{\mathrm{C}} \mathrm{T}$ because of our long-standing interest in studying the molecular mechanisms responsible for the binding, internalization and intracellular trafficking of tetanus neurotoxin, which continues to pose a serious threat to human health in the developing world. The second probe used in this study was an antibody against the extracellular domain of p $75^{\mathrm{NTR}}$, which has previously been shown to act as a reliable tool to monitor the internalization and long-range transport of p $75^{\text {NTR }}$ in a ligand-dependent manner (Deinhardt et al., 2007). Upon addition of neurotrophins, this antibody enters signaling endosomes containing $\mathrm{H}_{\mathrm{C}} \mathrm{T}$ and $\mathrm{Trk}$ receptors, which are retrogradely transported along the axon (Deinhardt et al., 2006).

Motor neurons are the most physiologically relevant model system with which to perform such a screen. We used HBG3 ES cells for differentiating large numbers of GFP-expressing motor neurons, which could be easily imaged for the quantification of fluorescent probe accumulation.

One aspect of the screen that underwent extensive optimization was the timing of internalization of the two probes. We performed a kinetic analysis of $\mathrm{H}_{\mathrm{C}} \mathrm{T}$ and $\mathrm{p} 75^{\mathrm{NTR}}$ internalization (Supplementary Figure 3) and established that the two probes behaved differently in their response to the cytoplasmic dynein 


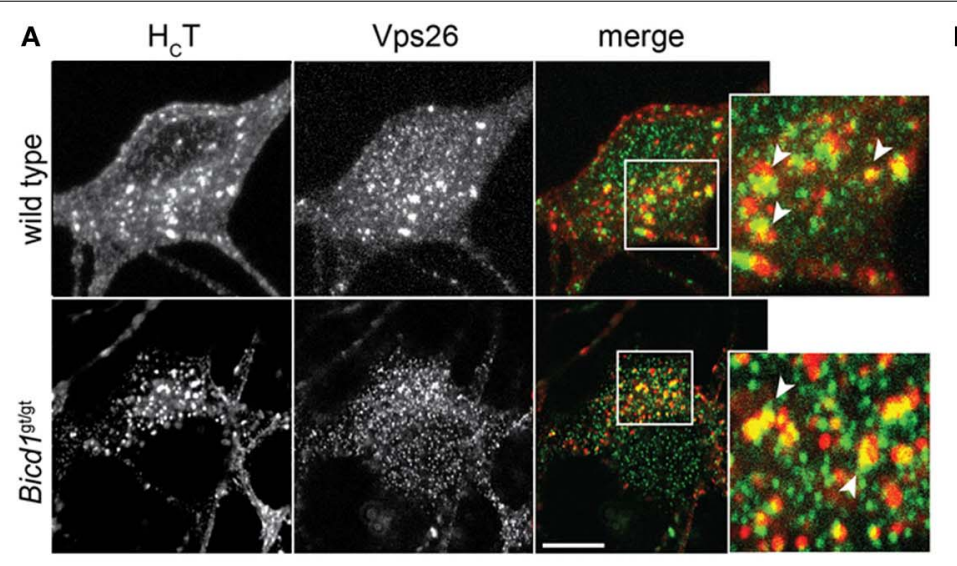

B

$\mathrm{H}_{\mathrm{C}} \mathrm{T}-\mathrm{Vps} 26$ colocalisation

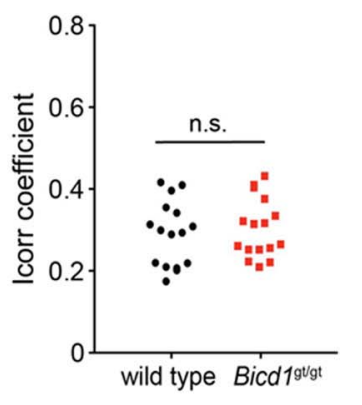

c BICD1-GFP
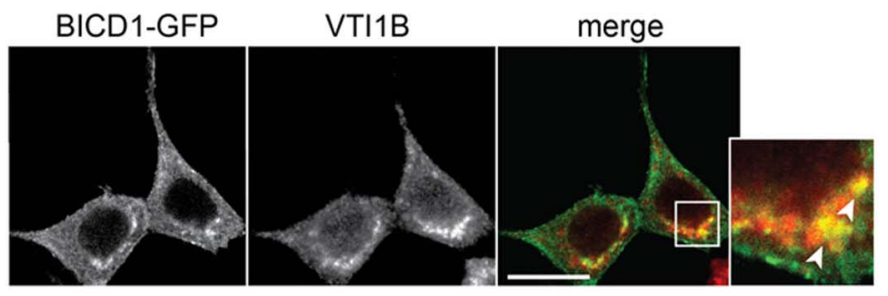

D

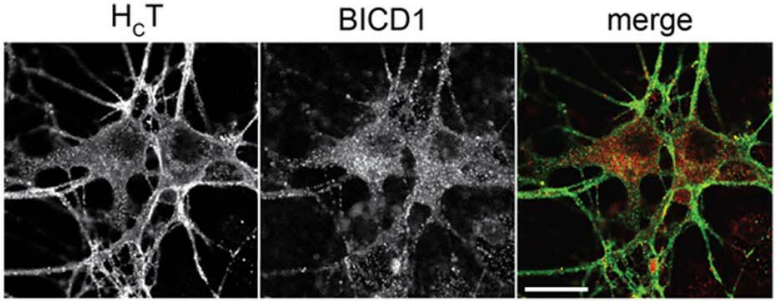

FIGURE $5 \mid \mathrm{H}_{\mathrm{C}} \mathrm{T}$ partially co-distributes with retromer components and late endosomal SNAREs. (A) Wild type and Bicd $7^{\mathrm{gt} / \mathrm{gt}}$ motor neurons were incubated with AlexaFluor555-conjugated $\mathrm{H}_{\mathrm{C}} \mathrm{T}$ (red) for $1 \mathrm{~h}$ at $37^{\circ} \mathrm{C}$, then acid-washed, fixed and immunostained for $\mathrm{Vps} 26$ (green). Insets from the merged images are magnified to show co-localization (yellow) between $\mathrm{H}_{\mathrm{C}} \mathrm{T}$ and Vps26. Scale bar, $5 \mu \mathrm{m}$. (B) Quantification of $\mathrm{H}_{\mathrm{C}} \mathrm{T} / \mathrm{Nps} 26$ co-localization from the experiment shown in (A) (16 cells per condition, Mann-Whitney test, mean \pm s.e.m., n.s. non-significant). (C) N2A cells

inhibitor EHNA, which was used in our screen as a positive control for inhibition of axonal transport. EHNA inhibited the accumulation of $\mathrm{H}_{\mathrm{C}} \mathrm{T}$, even from the earliest time points, whereas this inhibitor affected p75 ${ }^{\text {NTR }}$ accumulation only after $90 \mathrm{~min}$. A possible explanation for this phenomenon is that in the absence of neurotrophins, $\mathrm{p} 75^{\mathrm{NTR}}$ enters a local recycling pathway and does not undergo long-range axonal retrograde transport. Hence, treatment with EHNA would not be expected to change p75 $5^{\mathrm{NTR}}$ accumulation in the absence of any cognate ligands. However, $\mathrm{H}_{\mathrm{C}} \mathrm{T}$ is known to promote $\mathrm{p} 75^{\mathrm{NTR}}$ axonal transport (Deinhardt et al., 2007), thereby increasing the delivery of this receptor to the soma. This may be the most likely explanation for the increased p $75^{\text {NTR }}$ accumulation in the presence of $\mathrm{H}_{\mathrm{C}} \mathrm{T}$ and that EHNAinduced effects for p75 were only noted from 90 min onwards.

Our screen identified several genes that affected the internalization and/or accumulation of $\mathrm{H}_{\mathrm{C}} \mathrm{T}$ and $\alpha \mathrm{p} 75^{\mathrm{NTR}}$. For example, the knockdown of Rab7 increased the intracellular accumulation over-expressing BICD1-GFP (green) were fixed and immunostained for VTI1B (red). The white box in the merged channel is magnified to highlight the extent of co-localization of BICD1-GFP and this late endosomal SNARE protein. Scale bar, $20 \mu \mathrm{m}$. (D) Wild type motor neurons were incubated with AlexaFluor488-conjugated $\mathrm{H}_{\mathrm{C}}{ }^{\top}$ (green) for $1 \mathrm{~h}$ at $37^{\circ} \mathrm{C}$, acid-washed, fixed and then immunostained for BICD1 (red). Co-localization between $\mathrm{H}_{\mathrm{C}} \mathrm{T}$ and BICD1 was not detected under these conditions. Scale bar, $20 \mu \mathrm{m}$.

of $75^{\text {NTR }}$ (Figure 2B and Supplementary Table 1G), possibly due to the defective progression of this receptor along the endosomal pathway, a process known to be regulated by Rab7 (Stenmark, 2009; Mizuno-Yamasaki et al., 2012). This result is in agreement with the accumulation of NGF-activated TrkA in enlarged endosomes in PC12 cells overexpressing a dominantnegative Rab7 mutant (Saxena et al., 2005). Although our screen was performed in the absence of exogenous neurotrophins, $\mathrm{H}_{\mathrm{C}} \mathrm{T}$ has been found to activate neurotrophin signaling in a Trk-dependent manner (Calvo et al., 2012), and therefore may direct $\mathrm{p} 75^{\mathrm{NTR}}$ toward a long-range axonal trafficking pathway, which is normally only followed by ligand-activated receptors (Deinhardt et al., 2007).

Since the uptake and axonal transport of $\mathrm{H}_{\mathrm{C}} \mathrm{T}$ and $\mathrm{p} 75^{\mathrm{NTR}}$ share a common route (Bercsenyi et al., 2013; Schmieg et al., 2013), it was perhaps surprising that our screen failed to identify any gene equally affecting the intracellular dynamics of both 
probes. For instance, the cytoplasmic dynein/dynactin complex is known to play a key role in the axonal retrograde transport of both $\mathrm{H}_{\mathrm{C}} \mathrm{T}$ and $\mathrm{p} 75^{\mathrm{NTR}}$ (Bercsenyi et al., 2013). Of the many cytoplasmic dynein and dynactin genes that we screened, only the knockdown of dynein light chain Tctex-3 (Dynlt3) and p150 Glued (Dcnt1) reduced the accumulation of $\mathrm{H}_{\mathrm{C}} \mathrm{T}$ without affecting intracellular increase of $\alpha p 75^{\mathrm{NTR}}$ (Figure 2B and Supplementary Tables 1F,G). One possible explanation for this unexpected result is that the internalization and transport of $\mathrm{H}_{\mathrm{C}} \mathrm{T}$ and $\mathrm{p} 75^{\mathrm{NTR}}$ are differentially sensitive to the degree of silencing of genes that regulate their trafficking, such as dynein/dynactin subunits or specific Rab GTPases. Decreased accumulation phenotypes were more common for anterograde kinesin heavy chains, such as KIF11, KIF15, and KIF21B (Figure 2B and Supplementary Tables 1F,G). Experiments aimed at addressing the function of these kinesins in neurotrophin receptor trafficking will be the focus of future studies.

Since tetanus toxin traffics to the central nervous system by dynein-mediated retrograde transport and BICD1 is a known cytoplasmic dynein adaptor, we concentrated our efforts on investigating how BICD1 depletion affected the accumulation of $\mathrm{H}_{\mathrm{C}} \mathrm{T}$ in motor neurons. Our results suggest that BICD1 regulates $\mathrm{H}_{\mathrm{C}} \mathrm{T}$ trafficking, which may provide insights into how this dynein adaptor might influence tetanus toxin behavior in vivo. Furthermore, BICD1 is known to play diverse roles in the development and maintenance of the nervous system (Matanis et al., 2002; Schlager et al., 2010) yet its mechanism of action in this context has not been established. Because BICD1 was proposed to play a role in axonal retrograde transport (Wanschers et al., 2007) and is transported along axons (Figure 3A), we postulated that BICD1 depletion might interfere with long-range axonal trafficking of signaling endosomes containing $\mathrm{H}_{\mathrm{C}} \mathrm{T}$ and $\mathrm{p} 75^{\mathrm{NTR}}$. However, the axonal retrograde transport of $\mathrm{H}_{\mathrm{C}} \mathrm{T}$ was not perturbed in Bicd $1^{\mathrm{gt} / \mathrm{gt}}$ motor neurons (Figure 3B). Similarly, axonal trafficking of $\mathrm{p} 75^{\mathrm{NTR}}$ was also unaffected in Bicd $1^{\mathrm{gt} / \mathrm{gt}}$ motor neurons upon BDNF stimulation (Terenzio et al., 2014), suggesting that either BICD1 is not essential for the long-range axonal trafficking of $\mathrm{H}_{\mathrm{C}} \mathrm{T}$ and $\mathrm{p} 75^{\mathrm{NTR}}$, or that the residual BICD1 protein level in Bicd $1^{\text {gt/gt }}$ motor neurons is sufficient to support the recruitment of cytoplasmic dynein to $\mathrm{H}_{\mathrm{C}} \mathrm{T}$-containing signaling endosomes and/or the regulation of dynein activity associated with these endosomes.

Recently, the mechanisms responsible for cargo sorting within signaling endosomes and the fate of ligand-receptor complexes upon arrival in the cell body have gained mounting interest. Based on our analysis of $\mathrm{H}_{\mathrm{C}} \mathrm{T}$ trafficking, we hypothesized that BICD1 was likely to have a role in the somatic sorting of this probe. In support of this view, electron microscopy analyses performed in motor neurons depleted of BICD1 demonstrated that gold-conjugated $\mathrm{H}_{\mathrm{C}} \mathrm{T}$ exhibited a higher association with enlarged membrane compartments, where it clustered close to the limiting membrane, sometimes within bud-like structures connected to these organelles (Figure 4). This finding suggested that BICD1 is involved in the regulation of the endosomal trafficking of $\mathrm{H}_{\mathrm{C}} \mathrm{T}$ and neurotrophin receptor complexes and that its depletion alters cargo flow within the endosomal pathway.

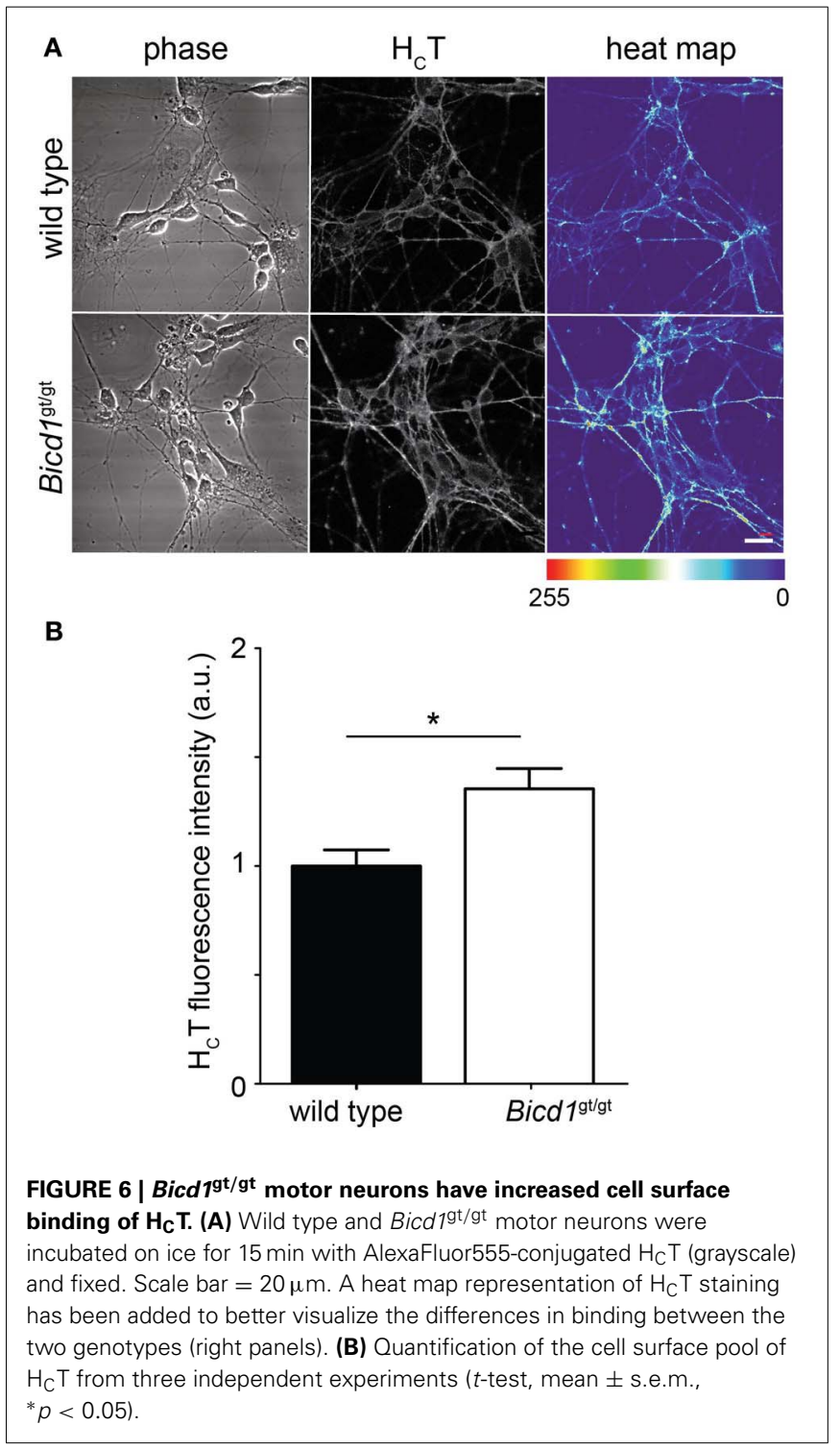

The retromer complex is a crucial component of the endosomal sorting machinery, and plays major roles in endosome to Golgi retrieval and endosome to plasma membrane recycling processes, through interactions with members of the sorting nexin (SNX) family (Seaman, 2012). Recently, more than 100 plasma membrane proteins were found to bind to SNX27, including the neurotrophin receptor scaffolding protein Kidins220/ARMS (Steinberg et al., 2013). Importantly, SNX27 is required to maintain plasma membrane levels of these proteins by promoting their recycling and preventing their degradation (Steinberg et al., 2013). We found that $\mathrm{H}_{\mathrm{C}} \mathrm{T}$ colocalizes with retromer components, such as Vps26 (Figure 5A), and SNX1 (Terenzio et al., 2014). Crucially, the co-distribution of $\mathrm{H}_{\mathrm{C}} \mathrm{T}$ with SNX1-positive compartments was higher in Bicd $1^{\text {gt/gt }}$ motor neurons compared to wild type cells, suggesting that SNX1-dependent sorting of $\mathrm{H}_{\mathrm{C}} \mathrm{T}$ and associated cargoes was affected by BICD1 depletion (Terenzio et al., 2014). 


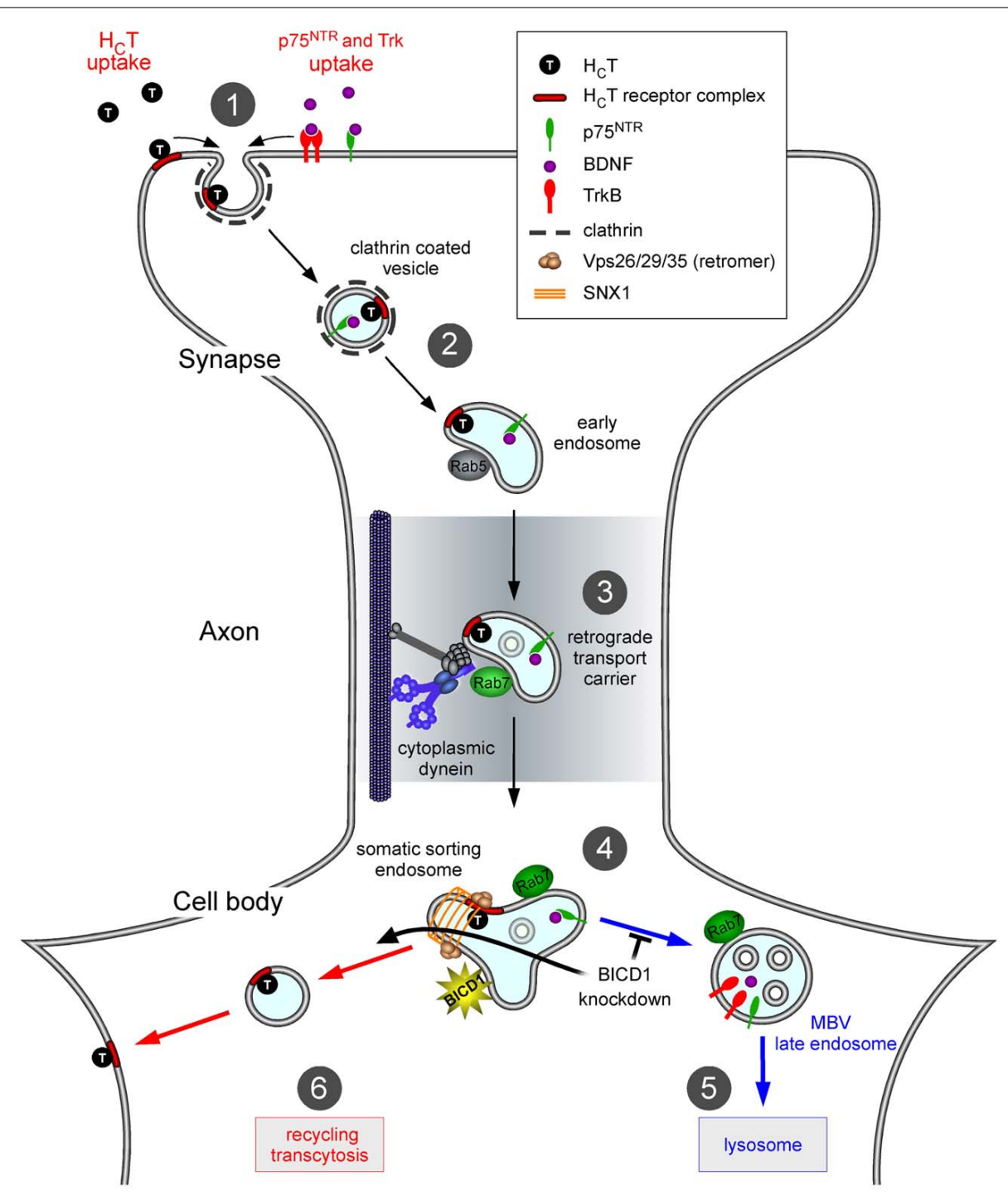

FIGURE 7 | Proposed role of BICD1 in $\mathbf{H}_{\mathbf{C}} \mathbf{T}$ trafficking. In wild type motor neurons, $\mathrm{H}_{\mathrm{C}} \mathrm{T}$ binds to plasma membrane receptors, which include polysialogangliosides and is internalized at synaptic sites located in the periphery (1); note that for clarity, internalization of $\mathrm{H}_{\mathrm{C}} \mathrm{T}$ along the axon and in the soma is not shown. $\mathrm{H}_{\mathrm{C}} \mathrm{T}$ and neurotrophin-receptor complexes are sorted to signaling endosomes (2), which are retrogradely transported by cytoplasmic dynein (3), toward the cell soma. Here, they associate with somatic sorting endosomes (4) decorated by sorting nexin 1 (SNX1) and other retromer components. Neurotrophin receptors are then trafficked toward MVB/lysosomes (5) for degradation, whilst $\mathrm{H}_{\mathrm{C}} \mathrm{T}$ is recycled to the plasma membrane (6). Impairment of the lysosomal targeting of TrkB and other proteins, including $\mathrm{H}_{\mathrm{C}} \mathrm{T}$ receptors, in neurons lacking BICD1 is envisaged to mainly redirect them to the recycling route back to the plasma membrane. The main consequence of these miss-sorting steps is an increase in $\mathrm{H}_{\mathrm{C}} \mathrm{T}$ binding sites and neurotrophin receptors (Terenzio et al., 2014) on the cell surface at steady state.
Supporting our proposed role for BICD1 in endosomal sorting, depletion of BICD1 increased plasma membrane levels of $\mathrm{H}_{\mathrm{C}} \mathrm{T}$ (Figure 6) as well as the neurotrophin-dependent recycling of $\mathrm{p} 75^{\mathrm{NTR}}$ and TrkB to the plasma membrane (Terenzio et al., 2014). At the present time, we do not have a molecular explanation for the increased cell surface binding of $\mathrm{H}_{\mathrm{C}} \mathrm{T}$ by Bicd $1^{\mathrm{gt} / \mathrm{gt}}$ motor neurons, but it is likely to relate to increased toxin receptor levels at the plasma membrane. Even though the protein receptor of $\mathrm{H}_{\mathrm{C}} \mathrm{T}$ is not known (Bercsenyi et al., 2013), this probe co-localizes with TrkB, undergoes axonal retrograde transport with this receptor (Deinhardt et al., 2006) and activates signaling cascades downstream of Trks in cortical and hippocampal neurons (Gil et al., 2000, 2003; Calvo et al., 2012).

Based on these results, we would like to propose a model by which BICD1 controls the sorting of cargoes within axonal signaling endosomes and subsequently directs them to appropriate degradation or recycling routes (Figure 7). This role, which is required for optimal neurotrophin signaling (Terenzio et al., 2014), is also likely to control the trafficking of pathogens and virulence factors, such as tetanus neurotoxin and its binding fragment $\mathrm{H}_{\mathrm{C}} \mathrm{T}$, which exploit axonal signaling endosomes for their entry and dissemination in the nervous system (Salinas et al., 
2010; Schmieg et al., 2013). In this light, modulating BICD1 activity could have potential therapeutic effects on the controlling the infectivity and/or spreading of viruses and toxins, and may be exploited to improve the efficiency of gene therapy vectors targeting the nervous system.

\section{AUTHOR CONTRIBUTIONS}

All authors provided substantial contributions to this work. In particular, Marco Terenzio and Giampietro Schiavo contributed to the conception, experimental design, data interpretation and drafting of the manuscript. Marco Terenzio contributed to the setup of the ES differentiation protocols and to data analysis. All authors contributed to manuscript revision and approval of the final version. All authors are accountable in ensuring that questions related to the accuracy or integrity of any part of the work are appropriately investigated and resolved.

\section{ACKNOWLEDGMENTS}

We thank Hynek Wichterle and Tom Jessell for HBG3 ES cells, Matthew Seaman for the Vps26 antibody, Ken Blight and Matthew R. G. Russell (Cancer Research UK London Research Institute) for assistance with electron microscopy, Mike Howell (Cancer Research UK London Research Institute) for help with establishing the siRNA screen and members of the Molecular Neuropathobiology Laboratory for constructive comments. This work was supported by Cancer Research UK, the Marie Curie Actions Human Resources and Mobility Training Network "Endocyte" (MRTN-CT-2006-035528; to Marco Terenzio). This project has received funding from the European Union's 7th Programme for research, technological development and demonstration under grant agreement FP7-222992 (to Giampietro Schiavo) and Weizmann-UK "Making Connections" grant (to Giampietro Schiavo).

\section{SUPPLEMENTARY MATERIAL}

The Supplementary Material for this article can be found online at: http://www.frontiersin.org/journal/10.3389/fncel. 2014.00140/abstract

\section{Supplementary Figure 1 | Optimization of the transfection protocol.}

(A) VAMP2 knockdown in primary motor neurons using different transfection reagents in a 96 well plate format. The spot count for VAMP2-positive vesicles for the reagents that proved non-toxic (12 out of the original 23) are shown. 2 different VAMP2 siRNA concentrations, 50 and $100 \mathrm{nM}$, were used for each reagent. (B) The most effective eight reagents from (A) were re-screened using the same protocol, but using three different concentrations of each reagent. The quantity of each reagent used is indicated. Samples treated with the indicated reagent and the siRNA control pool or the VAMP2 siRNA pool are indicated by S or V, respectively $(n=3)$. (C) The most effective four reagents from panel $\mathrm{B}$ were tested for their ability to induce knockdown of VAMP2. Western blotting of cell lysates demonstrated that all four reagents proved to be effective in downregulating VAMP2.

Supplementary Figure 2 | Derivation of motor neurons from mouse embryonic stem cells. (A) Flow diagram describing the protocol used for the differentiation of motor neurons from mouse HB9-GFP ES cells. After growth in suspension in differentiating medium for 3 days, the ES cells form embryoid bodies (EBs) comprising neuronal progenitor cells (NPC). These NPCs are then induced to commit to a motor neuron fate (indicated by GFP expression) by the addition of retinoic acid (RA) and Smoothened Agonist (SAG), a small molecule activator of sonic hedgehog signaling. At the end of the fourth day in the presence of these differentiating agents, the EBs are dissociated and motor neurons plated. Scale bar, $10 \mu \mathrm{m}$. (B) HB9-GFP ES cell derived motor neurons (GFP, green) 4 days after plating and immunostained for GFP (red) and the pan neuronal marker, $\beta I I I$ tubulin (blue). Note the characteristically long motor neuron axon (arrowhead), arising for the soma (asterisk). Scale bar, $50 \mu \mathrm{m}$.

\section{Supplementary Figure 3 | Kinetics of $\mathbf{H}_{\mathrm{C}} \mathbf{T}$ and $\mathbf{p 7 5 ^ { \mathrm { NTR } }}$ antibody} internalization. (A) $\mathrm{H}_{\mathrm{C}} \mathrm{T}$ accumulation kinetics in motor neurons derived from HB9-GFP ES cells in the presence of $\alpha \mathrm{p} 75^{\mathrm{NTR}}$ and the presence (red) or absence (black) of EHNA ( $n=3$ ). Note that $\mathrm{H}_{C} \mathrm{~T}$ accumulation was significantly decreased in the presence of EHNA $(p<0.0001$, Two-Ways ANOVA). (B) Accumulation kinetics of the p $75^{\mathrm{NTR}}$ antibody ( $\alpha p 75^{\mathrm{NTR}}$ ) when co-incubated with $\mathrm{H}_{\mathrm{C}} \mathrm{T}$ in motor neurons derived from HB9-GFP ES cells in the absence (black) or presence (red) of EHNA $(n=3)$. Note that the receptor accumulation profiles generated from EHNA-treated samples diverge from the control plot only after $75 \mathrm{~min}$ ( $p<0.0001$, Two-Ways ANOVA). Importantly, in the absence of $\mathrm{H}_{\mathrm{C}} \mathrm{T}$, the internalization kinetics of the p75 NTR antibody (blue) overlapped with the internalization profile observed for this probe when it was co-incubated with $\mathrm{H}_{\mathrm{C}} T$ and EHNA.

Supplementary Figure 4 | Assessment of knockdown efficiency of the siRNA screen. Five wells from each plate of the siRNA screen were treated with non-targeting control siRNA and five wells with VAMP2 siRNA. Protein lysates from each set of samples for each plate were pooled and analyzed by western blot to assess VAMP2 knockdown efficiency with $\beta$ III tubulin serving as a loading control.

Supplementary Figure 5 | Internalization kinetics of $\mathbf{H}_{\mathrm{C}} \mathbf{T}$ and $\mathbf{p} 75^{\mathrm{NTR}}$ antibody in wild type, Bicd $1^{\text {gt/ } /+}$ and Bicd $1^{\text {t }} / \mathrm{gt}^{\mathrm{gt}}$ motor neurons. (A) $\mathrm{H}_{\mathrm{C}} \mathrm{T}$ internalization kinetics were assessed in wild type, Bicd $19 \mathrm{gt} /+$ and Bicd $1^{\text {t/ } / g^{t}}$ motor neurons. At the $60 \mathrm{~min}$ time point, a statistically significant increase in $\mathrm{H}_{\mathrm{C}}$ T accumulation was confirmed for Bicd 1 $^{\mathrm{t}} / \mathrm{gt}$ motor neurons compared to wild type cells. (ANOVA test, followed by Bonferroni post-test, $n=3$. Results are shown \pm s.e.m.). (B) $\alpha p 75^{\mathrm{NTR}}$ antibody internalization kinetics were assessed in wild type, Bicd $7^{\mathrm{gt} /+}$ and Bicd $11^{\text {tt }} /$ t $^{\mathrm{t}}$ motor neurons. A statistically significant difference between the three genotypes was observed at the 60 min time point. Statistical significance was calculated using a One-Way ANOVA test, followed by Bonferroni post-test, $n=3$. Results are shown \pm s.e.m.

\section{REFERENCES}

Aguirre-Chen, C., Bulow, H. E., and Kaprielian, Z. (2011). C. elegans bicd-1, homolog of the Drosophila dynein accessory factor Bicaudal D, regulates the branching of PVD sensory neuron dendrites. Development 138, 507-518. doi: 10.1242/dev.060939

Bercsenyi, K., Giribaldi, F., and Schiavo, G. (2013). The elusive compass of clostridial neurotoxins: deciding when and where to go? Curr. Top. Microbiol. Immunol. 364, 91-113. doi: 10.1007/978-3-642-33570-9_5

Bianco, A., Dienstbier, M., Salter, H. K., Gatto, G., and Bullock, S. L. (2010). Bicaudal-D regulates fragile $\mathrm{X}$ mental retardation protein levels, motility, and function during neuronal morphogenesis. Curr. Biol. 20, 1487-1492. doi: 10. 1016/j.cub.2010.07.016

Bohnert, S., and Schiavo, G. (2005). Tetanus toxin is transported in a novel neuronal compartment characterized by a specialized $\mathrm{pH}$ regulation. J. Biol. Chem. 280, 42336-42344. doi: 10.1074/jbc.M506750200 
Bronfman, F. C., Escudero, C. A., Weis, J., and Kruttgen, A. (2007). Endosomal transport of neurotrophins: roles in signaling and neurodegenerative diseases. Dev. Neurobiol. 67, 1183-1203. doi: 10.1002/dneu.20513

Calvo, A. C., Olivan, S., Manzano, R., Zaragoza, P., Aguilera, J., and Osta, R. (2012). Fragment $\mathrm{C}$ of tetanus toxin: new insights into its neuronal signaling pathway. Int. J. Mol. Sci. 13, 6883-6901. doi: 10.3390/ijms13066883

Deinhardt, K., Reversi, A., Berninghausen, O., Hopkins, C. R., and Schiavo, G. (2007). Neurotrophins Redirect p $75^{\mathrm{NTR}}$ from a clathrin-independent to a clathrin-dependent endocytic pathway coupled to axonal transport. Traffic 8, 1736-1749. doi: 10.1111/j.1600-0854.2007.00645.x

Deinhardt, K., Salinas, S., Verastegui, C., Watson, R., Worth, D., Hanrahan, S., et al. (2006). Rab5 and Rab7 control endocytic sorting along the axonal retrograde transport pathway. Neuron 52, 293-305. doi: 10.1016/j.neuron.2006.08.018

Deinhardt, K., and Schiavo, G. (2005). Endocytosis and retrograde axonal traffic in motor neurons. Biochem. Soc. Symp. 72, 139-150.

Demir, K., and Boutros, M. (2012). Cell perturbation screens for target identification by RNAi. Methods Mol. Biol. 910, 1-13. doi: 10.1007/978-1-61779965-5_1

Echeverri, C. J., Beachy, P. A., Baum, B., Boutros, M., Buchholz, F., Chanda, S. K., et al. (2006). Minimizing the risk of reporting false positives in large-scale RNAi screens. Nat. Methods 3, 777-779. doi: 10.1038/nmeth1006-777

Gil, C., Chaib-Oukadour, I., and Aguilera, J. (2003). C-terminal fragment of tetanus toxin heavy chain activates Akt and MEK/ERK signalling pathways in a Trk receptor-dependent manner in cultured cortical neurons. Biochem. J. 373, 613-620. doi: 10.1042/BJ20030333

Gil, C., Chaib-Oukadour, I., Pelliccioni, P., and Aguilera, J. (2000). Activation of signal transduction pathways involving trkA, PLCgamma-1, PKC isoforms and ERK-1/2 by tetanus toxin. FEBS Lett. 481, 177-182. doi: 10.1016/S0014-5793 (00)02002-0

Hafezparast, M., Klocke, R., Ruhrberg, C., Marquardt, A., Ahmad-Annuar, A., Bowen, S., et al. (2003). Mutations in dynein link motor neuron degeneration to defects in retrograde transport. Science 300, 808-812. doi: 10.1126/science. 1083129

Heerssen, H. M., and Segal, R. A. (2002). Location, location, location: a spatial view of neurotrophin signal transduction. Trends Neurosci. 25, 160-165. doi: 10.1016/ S0166-2236(02)02144-6

Hoogenraad, C. C., Akhmanova, A., Howell, S. A., Dortland, B. R., De Zeeuw, C. I., Willemsen, R., et al. (2001). Mammalian Golgi-associated Bicaudal-D2 functions in the dynein-dynactin pathway by interacting with these complexes. EMBO J. 20, 4041-4054. doi: 10.1093/emboj/20.15.4041

Krausz, E. (2007). High-content siRNA screening. Mol. Biosyst. 3, 232-240. doi: 10. 1039/b616187c

Lalli, G., Gschmeissner, S., and Schiavo, G. (2003). Myosin Va and microtubulebased motors are required for fast axonal retrograde transport of tetanus toxin in motor neurons. J. Cell Sci. 116, 4639-4650. doi: 10.1242/jcs.00727

Lalli, G., and Schiavo, G. (2002). Analysis of retrograde transport in motor neurons reveals common endocytic carriers for tetanus toxin and neurotrophin receptor p75NTR. J. Cell Biol. 156, 233-239. doi: 10.1083/jcb.200106142

Lefebvre, L., Dionne, N., Karaskova, J., Squire, J. A., and Nagy, A. (2001). Selection for transgene homozygosity in embryonic stem cells results in extensive loss of heterozygosity. Nat. Genet. 27, 257-258. doi: 10.1038/85808

Li, X., Kuromi, H., Briggs, L., Green, D. B., Rocha, J. J., Sweeney, S. T., et al. (2010). Bicaudal-D binds clathrin heavy chain to promote its transport and augments synaptic vesicle recycling. EMBO J. 29, 992-1006. doi: 10.1038/emboj.2009.410

Matanis, T., Akhmanova, A., Wulf, P., Del Nery, E., Weide, T., Stepanova, T., et al. (2002). Bicaudal-D regulates COPI-independent Golgi-ER transport by recruiting the dynein-dynactin motor complex. Nat. Cell Biol. 4, 986-992. doi: 10. 1038/ncb891

Mizuno-Yamasaki, E., Rivera-Molina, F., and Novick, P. (2012). GTPase networks in membrane traffic. Ann. Rev. Biochem. 81, 637-659. doi: 10.1146/annurevbiochem-052810-093700

Offenhauser, C., Lei, N., Roy, S., Collins, B. M., Stow, J. L., and Murray, R. Z. (2011). Syntaxin 11 binds Vtilb and regulates late endosome to lysosome fusion in macrophages. Traffic 12, 762-773. doi: 10.1111/j.1600-0854.2011.01189.x

Ohka, S., Sakai, M., Bohnert, S., Igarashi, H., Deinhardt, K., Schiavo, G., et al. (2009). Receptor-dependent and -independent axonal retrograde transport of poliovirus in motor neurons. J. Virol. 83, 4995-5004. doi: 10.1128/JVI. 02225-08

Parton, R. G., Ockleford, C. D., and Critchley, D. R. (1987). A study of the mechanism of internalisation of tetanus toxin by primary mouse spinal cord cultures. J. Neurochem. 49, 1057-1068. doi: 10.1111/j.1471-4159.1987. tb09994.x

Restani, L., Giribaldi, F., Manich, M., Bercsenyi, K., Menendez, G., Rossetto, O., et al. (2012). Botulinum neurotoxins $A$ and $E$ undergo retrograde axonal transport in primary motor neurons. PLoS Pathog. 8:e1003087. doi: 10.1371/journal. ppat. 1003087

Salinas, S., Bilsland, L. G., Henaff, D., Weston, A. E., Keriel, A., Schiavo, G., et al. (2009). CAR-associated vesicular transport of an adenovirus in motor neuron axons. PLoS Pathog. 5:e1000442. doi: 10.1371/journal.ppat.1000442

Salinas, S., Schiavo, G., and Kremer, E. J. (2010). A hitchhiker's guide to the nervous system: the complex journey of viruses and toxins. Nat. Rev. Microbiol. 8, 645-655. doi: 10.1038/nrmicro2395

Saxena, S., Bucci, C., Weis, J., and Kruttgen, A. (2005). The small GTPase Rab7 controls the endosomal trafficking and neuritogenic signaling of the nerve growth factor receptor TrkA. J. Neurosci. 25, 10930-10940. doi: 10.1523/JNEUROSCI. 2029-05.2005

Schlager, M. A., Kapitein, L. C., Grigoriev, I., Burzynski, G. M., Wulf, P. S., Keijzer, N., et al. (2010). Pericentrosomal targeting of Rab6 secretory vesicles by Bicaudal-D-related protein 1 (BICDR-1) regulates neuritogenesis. EMBO J. 29, 1637-1651. doi: 10.1038/emboj.2010.51

Schmieg, N., Menendez, G., Schiavo, G., and Terenzio, M. (2013). Signalling endosomes in axonal transport: travel updates on the molecular highway. Semin. Cell Dev. Biol. doi: 10.1016/j.semcdb.2013.10.004

Schoch, S., Deak, F., Konigstorfer, A., Mozhayeva, M., Sara, Y., Sudhof, T. C., et al. (2001). SNARE function analyzed in synaptobrevin/VAMP knockout mice. Science 294, 1117-1122. doi: 10.1126/science.1064335

Seaman, M. N. (2012). The retromer complex-endosomal protein recycling and beyond. J. Cell Sci. 125, 4693-4702. doi: 10.1242/jcs.103440

Steinberg, F., Gallon, M., Winfield, M., Thomas, E. C., Bell, A. J., Heesom, K. J., et al. (2013). A global analysis of SNX27-retromer assembly and cargo specificity reveals a function in glucose and metal ion transport. Nat. Cell Biol. 15, 461-471. doi: $10.1038 / \mathrm{ncb} 2721$

Stenmark, H. (2009). Rab GTPases as coordinators of vesicle traffic. Nat. Rev. Mol. Cell Biol. 10, 513-525. doi: 10.1038/nrm2728

Terenzio, M., Golding, M., Russell, M. R. G., Wicher, K., Rosewell, I., Spencer-Dene, B., et al. (2014). Bicaudal-D1 regulates the intracellular sorting and signalling of neurotrophin receptors. EMBO J. (in press).

Terenzio, M., and Schiavo, G. (2010). The more, the better: the BICD family gets bigger. EMBO J. 29, 1625-1626. doi: 10.1038/emboj.2010.78

Wanschers, B. F., Van De Vorstenbosch, R., Schlager, M. A., Splinter, D., Akhmanova, A., Hoogenraad, C. C., et al. (2007). A role for the Rab6B BicaudalD1 interaction in retrograde transport in neuronal cells. Exp. Cell Res. 313, 3408-3420. doi: 10.1016/j.yexcr.2007.05.032

Wichterle, H., Lieberam, I., Porter, J. A., and Jessell, T. M. (2002). Directed differentiation of embryonic stem cells into motor neurons. Cell 110, 385-397. doi: 10.1016/S0092-8674(02)00835-8

Conflict of Interest Statement: The authors declare that the research was conducted in the absence of any commercial or financial relationships that could be construed as a potential conflict of interest.

Received: 04 March 2014; accepted: 01 May 2014; published online: 20 May 2014. Citation: Terenzio M, Golding M and Schiavo G (2014) siRNA screen of ES cell-derived motor neurons identifies novel regulators of tetanus toxin and neurotrophin receptor trafficking. Front. Cell. Neurosci. 8:140. doi: 10.3389/fncel.2014.00140

This article was submitted to the journal Frontiers in Cellular Neuroscience.

Copyright (c) 2014 Terenzio, Golding and Schiavo. This is an open-access article distributed under the terms of the Creative Commons Attribution License (CC BY). The use, distribution or reproduction in other forums is permitted, provided the original author(s) or licensor are credited and that the original publication in this journal is cited, in accordance with accepted academic practice. No use, distribution or reproduction is permitted which does not comply with these terms. 